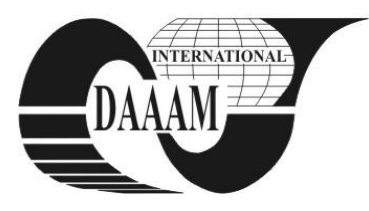

Annals of DAAAM for 2012 \& Proceedings of the 23rd International DAAAM Symposium, Volume 23, No.1, ISSN 2304-1382 ISBN 978-3-901509-91-9, CDROM version, Ed. B. Katalinic, Published by DAAAM International, Vienna, Austria, EU, 2012 Make Harmony between Technology and Nature, and Your Mind will Fly Free as a Bird Annals \& Proceedings of DAAAM International 2012

\title{
GOAL PROGRAMMING NUTRITION OPTIMIZATION MODEL
}

\author{
PASIC, M[ugdim]; CATOVIC, A[mra]; BIJELONJA, I[zet] \& BAHTANOVIC, A[mina]
}

\begin{abstract}
The aim of this paper is to develop a goal programming nutrition optimization model to meet daily nutrients needs of the reference woman and the reference man subject to the available household budget. Objective function in the model is designed in a way to minimize deviations from the defined micronutrients and macronutrients needs as well as from the food cost. The nutrients needs are determined according the World Health Organization (WHO) standards and are incorporated in the model constraints. The sample in this research consists of 55 most frequently used food items as decision variables which are selected based on a survey of 50 households in the capital of Bosnia and Herzegovina. As the result, the solution of the model is optimal selection of the food intake, subject to minimize deviations from the defined goals.

Keywords: goal programming, optimization, nutrients, food cost, constraints
\end{abstract}

\section{INTRODUCTION}

Proper intake of the food is the key aspect of the human health. The selection of the consumed food is usually done intuitively and many times it is subject of a trade off between available household budget for food and the micronutrient and macronutrients needs. Mathematical programming techniques can be applied to optimize both micronutrients and macronutrients needs and available household budget.

Study [1] presents the application of goal programming to determine the diet of children aged from 9 to11 months in Bogor District in Indonesia, which will satisfy the recommended values of nutrients taking into account the usual dietary habits and acceptable food cost. Indonesia is selected because of the high prevalence of malnutrition of children, a large number of preschool children and poor nutrition.

Research [2] develops a goal programming model that will reduce cost for food, and satisfy the required amounts of nutrients. The study is conducted in Nigeria, where the data analysis found that $65,45 \%$ of rural households have inadequate nutrition. The results show that a significantly smaller amount of food can satisfy the required amounts of nutrients.

Reference [3] shows the application of goal programming for optimization agriculture of the local population in the Savannah zone of Nigeria, to ensure enough food for their families, increase the cash income and minimize the use of hired labor. Goal programming is used to distribute the resources of farmers (land, labor and capital) with the aim of an optimal combination of crops that will satisfy the needs of farmers.
In research [4], the weighted goal programming is used for resources allocation of the population to ensure sufficient quantities of food. The constraints in the model are arable land, labour, dietary requirements, requirements for livestock grazing and the demands for products for both food and domestic energy needs.

Paper [5] investigates the difference between the models of linear and goal programming. Models are used for determining the nutrition of Thais that will satisfy the need for nutrients. Linear programming results give the minimal food cost as the goal function. Goal programming technique minimizes deviations from the recommended nutrient values as the goal function while increasing the food cost.

Article [6] shows that using the goal programming the diabetic diet can be calculated in terms of intake of certain nutrients. The results show that the goal programming can quickly determine the diet of diabetics where the nutrient values are closer to the recommended nutrient values than the manual calculation.

Research [7] analysis how various factors such as age, gender, weight, degree of obesity or thinness, ambient temperature, pregnancy and lactation, at rest or performing activities affecting the caloric requirements of individuals. The model predicts how changes in the environment, activities, and demographic characteristics affect the actual energy consumption of the population. The results show the energy value as a function of gender, age, activity level and also show how these values differ from the recommended values by the Food Agriculture Organization (FAO).

Reference [8] develops optimization diet models for the reference man and the reference woman using linear programming optimization technique. Objective function in the model is food cost, while constraints are defined as daily needs for macronutrients and micronutrients in accordance with the standards of the World Health Organization (WHO) and National Academic Press (NAP). The results of the research show the optimum amount of food that will minimize the food cost and satisfy daily needs for macronutrients and micronutrients. In a case of the limited household budget which can not satisfy minimal food cost obtained by linear programming technique it is not possible to meet recommended needs for micronutrients and macronutrients and goal programming technique can be used to make the compromise between household food budget and proper food intake.

The aim of this study is to develop optimal feeding patterns of the reference woman and the reference man 
using goal programming. Multiple goals are defined to meet daily nutrient needs and minimal daily feeding cost.

As results of the developed goal programming model in this paper, optimal selection of the food intake subject to minimize deviations from the WHO recommended micronutrients and macronutrients intakes, including energy needs, and available household budget for food is obtained.

Model developed in this paper assumed equal weights to all goals. So, future research will be focused on defining specific weights to different deviations of micronutrients and macronutrients as well as of available household budget.

\section{RESEARCH METHODOLOGY}

Dietary patterns are connected with well defined clinical entity such as anemia, muscle weakness, rachitic, infections and other diseases which can be induced by an excess or deficiency of nutrient intake. A healthful diet can be reached throughout the intake of multiple combinations of foods.

The food-based dietary guideline focuses on how a combination of foods can reach nutrient requirements rather than on how each specific nutrient is provided in adequate amounts. One of the earliest dietary guideline based on the mathematical principle of a food intake food from different groups was made by Sherman. Nutrient intake goal is to promote general health and control of specific nutritional diseases. In practice the set of food combinations which provide nutritional adequacy is limited by household budget.

In this study the focus is on caloric requirements as well. There are several available models for prediction of human caloric requirements. This research uses recommendations of World Health Organization. These recommendations include proportions of macronutrients (fats, carbohydrates as well as proteins) in energy intake.

As micronutrient adequacy must be included in evaluating the nutritive value of diets, beside the energy some micronutrients are included too. The most frequent health problems are connected to vitamins $\mathrm{A}, \mathrm{D}, \mathrm{E}, \mathrm{K}$, $\mathrm{B}_{6}, \mathrm{~B}_{9}, \mathrm{~B}_{12}, \mathrm{C}$ and minerals such as calcium, sodium, zinc and iron. In the model for each every nutrient daily intake recommendation there is RNI value (Recommended Nutrient Intake: the reference daily intake - the daily intake level of a nutrient that is considered to be sufficient to meet the requirements of $97 \%$ to $98 \%$ of healthy individuals) and UL value (Upper Limit: the highest average daily nutrient intake level that is likely to pose no risk of adverse health effects to almost all individuals in the general population. As intake increases above the UL value, the potential risk of adverse effects may increase).

Although many phytochemicals are bioactive, they are not considered as nutrients since they are not essential in the diet and there is no daily requirement. Because of their benefits for human health there is request of minimum of 400 grams of daily intake of fruits and vegetables in the model.

The fat is a major source of energy for the human body and helps absorption of fat-soluble vitamins and other food components such as carotenoids. The percent of energy that is consumed as a fat can vary from $15 \%$ to $30 \%$.

Saturated fatty acids are synthesized by the body and those intake from diet have adverse effect on health and thus are not required. Therefore in the model RNI is not required. Only UL for this nutrient is defined as $10 \%$ of daily energy intake.

Monounsaturated fatty acids can be synthesized by the body, and those taken from diet have beneficial role in preventing chronic diseases. In the model they range from $10 \%$ to $14 \%$ of energy intake. The n6 and n3 polyunsaturated fatty acids are essential. A deficiency of n6 polyunsaturated fatty acids is characterized by rough and scaly skin, dermatitis while $\mathrm{n} 3$ polyunsaturated fatty acids play an important role as structural membrane lipids, particularly in nerve tissue and the retina of the eye. In the model n6 range from $5 \%$ to $8 \%$, and $\mathrm{n} 3$ from $1 \%$ to $2 \%$ of energy intake.

Proteins form the major structural components of all cells of the body. They are included in production of energy too. By WHO recommendation percentage of caloric participation of proteins ranges from $10 \%$ to $15 \%$. In the model single amino acids are not considered, but there is constraint that the ratio of proteins from plant and animal source foods is $1: 1$.

Carbohydrates (sugars and starches) provide energy to cells in the body, particularly the brain, which is a carbohydrate-dependent organ. In the model carbohydrate requirement is from $50 \%$ to $70 \%$.

The reference woman and the reference man are considered in developing the model of goal programming to design healthy nutrition pattern. According to definition, the reference woman is healthy female person aged 25 with an average weight of $55 \mathrm{~kg}$ and low active lifestyle, while the reference man is healthy male person aged 25 with an average weight of $65 \mathrm{~kg}$ and low active lifestyle.

Data of 55 most frequently consumed food commodities are used for this study. These data are collected during two months period in February and March in 2011 using carefully designed questionnaire carried out in a random sample of 50 households in the capital of Bosnia and Herzegovina. Included food commodities are: 11 from cereals group (including snacks), 8 from fats group, 7 from meat, fish and eggs group, 7 from milk and dairy products group, 10 from vegetables group, 10 from fruits group and 3 from sugar and sugary concentrate group.

Prices of included food commodities in the research are the market prices expressed in local currency Convertible Mark (KM).

\section{MATHEMATICAL MODEL AND RESULTS}

Goal programming mathematical model is expected to minimize sum of deviations of WHO recommended daily micronutrients and macronutrients needs as well as of available household food budget. 
Decision variables in the model represent 55 different food commodities. Number of the model constraints, $n$, includes 37 for both RNI and UL values of nutrients, 1 for food cost and 1 for recommended values of energy intake, which counts for total of 39 constraints.

Objective function in the model is defined as:

$$
\text { Minimize } Z=\sum_{i=1}^{n}\left(d_{i}^{-}+d_{i}^{+}\right)
$$

where:

$d_{i}^{-}, d_{i}^{+}$are positive and negative deviational variables representing deviations from the $i^{\text {th }}$ goal.

For the RNI constraints positive deviation $d_{i}^{+}=0$, while for the UL constraints negative deviation $d_{i}^{-}=0$.

In the case of micronutrients and macronutrients requirements the objective function is subject to the following constraints:

$$
\sum_{j=1}^{m} a_{i j} \cdot x_{j}+\left(d_{i}^{-}-d_{i}^{+}\right)=g_{i}
$$

where:

$i=1$ to 37 , number of constraints

$m=55$, number of food commodities

$x_{j}=$ decision variables representing mass of the selected food commodities expressed in grams

$a_{i j}=$ content of the $i^{t h}$ nutrient in the $j^{\text {th }}$ food commodity

$$
g_{i}=\mathrm{RNI} \text { or UL }
$$

The objective function is subject to the following constraint with respect to the energy value, $e$ :

$$
\sum_{j=1}^{m} b_{j} \cdot x_{j}+\left(d_{e}^{-}-d_{e}^{+}\right)=e
$$

where:

$b_{j}=$ energy quantity per grams for the $j^{\text {th }}$ food commodity

$d_{e}^{-}, d_{e}^{+}=$positive and negative deviations from the recommended energy value

The objective function is also subject to the following constraint with respect to the food cost:

$$
\sum_{j=1}^{m} c_{j} \cdot x_{j}+\left(d_{c}^{-}-d_{c}^{+}\right)=C
$$

where:

$c_{j}=$ cost per gram of $j^{\text {th }}$ food commodity

$d_{c}^{-}, d_{c}^{+}=$positive and negative deviations from the food cost

\section{$C=$ household food budget constraint}

WHO recommends daily intake at least 400 grams of raw vegetables and fruits in order to prevent chronically diseases like heart diseases, cancer, diabetes as well as prevention of lack of micronutrients, especially in less developed countries. For that reason in the model an additional constraint is included that intake of raw vegetables and fruits must be at least 400 grams.

Target available household budget in the model is 2,5

\begin{tabular}{|c|c|c|c|c|}
\hline & \multicolumn{2}{|c|}{ Woman } & \multicolumn{2}{|c|}{ Man } \\
\hline Energy (kcal) & \multicolumn{2}{|c|}{2017} & \multicolumn{2}{|c|}{2590} \\
\hline Limits & RNI & UL & RNI & UL \\
\hline Polysaccharides $(\mathrm{g})$ & 246 & 344 & 316 & 442 \\
\hline Sugar $(\mathrm{g})$ & - & 49 & - & 63 \\
\hline Protein $(\mathrm{g})$ & 49 & 74 & 63 & 95 \\
\hline Saturated fatty acid $(\mathrm{g})$ & - & 22 & - & 28 \\
\hline Monounsaturated fatty acids $(\mathrm{g})$ & 22 & 30 & 28 & 39 \\
\hline $\mathrm{n} 3(\mathrm{~g})$ & 2 & 4 & 3 & 6 \\
\hline $\mathrm{n} 6(\mathrm{~g})$ & 11 & 17 & 14 & 22 \\
\hline Diet fibers $(\mathrm{g})$ & 27 & 40 & 27 & 40 \\
\hline Vitamin A $(\mu \mathrm{g})$ & 270 & 500 & 300 & 600 \\
\hline Vitamin D $(\mu \mathrm{g})$ & 5 & 50 & 5 & 50 \\
\hline Vitamin E (mg) & 15 & 1000 & 15 & 1000 \\
\hline Vitamin K $(\mu \mathrm{g})$ & 55 & - & 65 & - \\
\hline Vitamin B6 (mg) & 1,3 & 100 & 1,3 & 100 \\
\hline Vitamin B9 $(\mu \mathrm{g})$ & 400 & 1000 & 400 & 1000 \\
\hline Vitamin B12 $(\mu \mathrm{g})$ & 2,4 & 1000 & 2,4 & 1000 \\
\hline Vitamin C (mg) & 45 & 1000 & 45 & 1000 \\
\hline $\mathrm{Ca}(\mathrm{mg})$ & 1000 & 3000 & 1000 & 3000 \\
\hline $\mathrm{Na}(\mathrm{mg})$ & 1000 & 2000 & 1000 & 2000 \\
\hline $\mathrm{Zn}(\mathrm{mg})$ & 4,9 & 45 & 7 & 45 \\
\hline $\mathrm{Fe}(\mathrm{mg})$ & 18 & 45 & 8 & 45 \\
\hline
\end{tabular}
$\mathrm{KM}$ per person daily and is estimated based on average household income in Bosnia and Herzegovina.

Tab. 1. shows WHO defined RNI and UL for the reference woman and the reference man.

Tab. 1. Energy, RNI and UL micronutrient and macronutrient intake

A standard software package is used to solve developed goal programming optimization model and generate results of the optimization.

Results of the optimization model show that all deviational variables for nutrient needs are equal zero. It means that for the reference woman and the reference man all nutrients needs are met. Deviation different from zero is only $d_{c}^{+}$. For the reference woman positive deviation $d_{c}^{+}=0,54 \mathrm{KM}$, while positive deviation $d_{c}^{+}=0,89 \mathrm{KM}$ for the reference man. It means that the reference woman spends 3,04 KM, and the reference man spends 3,39 KM to meet all daily nutrient requirements.

Tab. 2 shows model results for food commodities for the reference woman while Tab. 3 shows model results for food commodities for the reference man.

Fig. 1 presents model results of the group food commodities percentage share for the reference woman, while Fig. 2 depicts model results of group food commodities percentage share for the reference man.

\begin{tabular}{|c|c|c|}
\hline & Food Commodity & Quantity [g] \\
\hline \multirow{3}{*}{ Cereals } & Corn wheat & 149,95 \\
\cline { 2 - 3 } & Oat wheat & 76,08 \\
\cline { 2 - 3 } & Rise & 121,55 \\
\cline { 2 - 3 } & Cornflake & 23,76 \\
\hline \multirow{2}{*}{ Fats } & Sunflower oil & 27,81 \\
\cline { 2 - 3 } & Walnut & 8,35 \\
\hline \multirow{2}{*}{$\begin{array}{c}\text { Meat, fish, eggs } \\
\text { Milk and dairy } \\
\text { products }\end{array}$} & Canned sardine & 66,63 \\
\cline { 2 - 3 } & Canned tuna & 4,13 \\
\hline Vegetables & Cheese & 41,14 \\
\hline
\end{tabular}

Tab. 2. Model results for food commodities for the reference woman 


\begin{tabular}{|c|c|c|}
\hline \multirow{2}{*}{ Cereals } & Food Commodity & Quantity [g] \\
\hline \multirow{2}{*}{ Fats } & Corn wheat & 39,84 \\
\cline { 2 - 3 } & Oat wheat & 98,91 \\
\cline { 2 - 3 } & Rise & 321,51 \\
\cline { 2 - 3 } & Cornflake & 6,89 \\
\hline \multirow{2}{*}{ Meat, fish, eggs } & Sunflower oil & 30,46 \\
\cline { 2 - 3 } & Walnut & 13,5 \\
\hline Milk and dairy products & Canned sardine & 64,82 \\
\hline \multirow{2}{*}{ Vegetable } & Cheese & 69,17 \\
\cline { 2 - 3 } & Carrot & 6,02 \\
\hline \multirow{2}{*}{ Fruit } & Cabbage & 78,31 \\
\cline { 2 - 3 } & Apple & 313,02 \\
\hline
\end{tabular}

Tab. 3. Model results for food commodities for the reference man

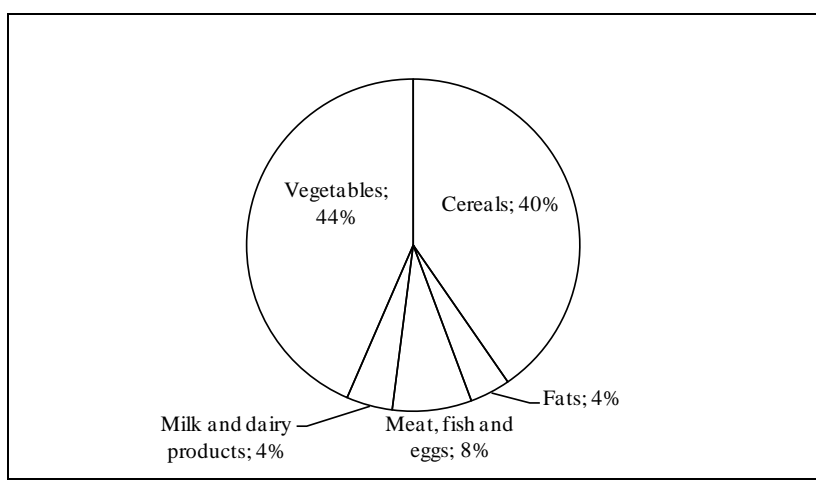

Fig. 1. Group food commodities percentages for the reference woman

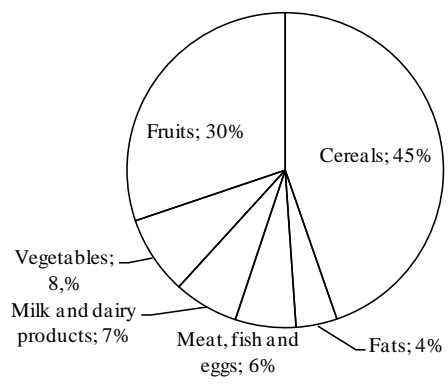

Fig. 2. Group food commodities percentages for the reference man

Fig. 3 depicts calories percentages share with respect to the group food commodities for both female and male.

To show the influence of the lack of household budget for food, the model was tested in a way that positive deviation variable from the food cost $d_{c}^{+}$is fixed at zero. As expected, the results of the model prove that not all deviation variables $d_{i}^{-}$are equal zero. In the case of the reference woman $\mathrm{n} 3$, vitamin $\mathrm{D}$ and vitamin $\mathrm{E}$ are underachieved. In the case of the reference man polysaccharides and $\mathrm{n} 3$ are underachieved and diet fibers are overachieved.

\section{CONCLUSION}

The results of this research show that for the reference woman and the reference man it is possible to develop reliable goal programming mathematical model in order to make compromise between the food cost and micronutrients and macronutrients intake.

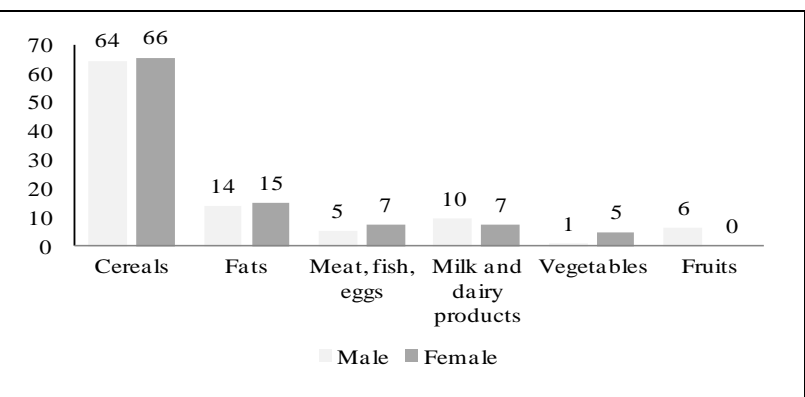

Fig. 3. Calories percentages share with respect to the group of food commodities

Limitation of the model is that it is developed for daily needs of the reference woman and the reference man and thus does not include food variety consumption as the function of a time as it is natural human need.

Since model developed in this paper assumed equal weights to all goals, future research will be focused on defining priority and specific weights to defined goals according to international organization standards and recommendations.

The final aim should be to develop weekly food pyramid for the reference woman and the reference man.

\section{REFERENCES}

[1] Santika, O., Fahmida, U. and Ferguson, E. L. (2009). Development of Food-Based Complementary Feeding Recommendations for 9- to 11-Month-Old-Peri-Urban Indonesian Infants Using Linear Programming, The Journal of Nutrition, Vol. 139, No. 1, 2009, pp. 135-141, ISSN 0022-3166

[2] Omotesho, O. A. and Muhammad-Lawal, A. (2010). Optimal Food Plan For Rural Households' Food Security In Kwara State, Nigeria: The Goal Programming Approach, Journal of Agricultural Biotechnology and Sustainable Development, Vol. 2(1), January 2010, pp. 007-014, ISSN 2141-2340

[3] Adejobi, A. O., Kormawa P. M., Manyong, V. M., and Olayemi, J. K. (2003). Optimal Crop Combinations Under Limited Resource Conditions: Application of Linear Goal Programming (LGP) Model to Smallholder Farmers in the Drier Savannah Zone of Nigeria, Proceedings of Deutscher Tropentag "Technological and Institutional Innovations for Sustainable Rural Development", October 8-10, Göttingen, ISBN: 3-9808714-3-6, Clemens W. et al. (Ed.), Centre for Tropical and Subtropical Agriculture and Forestry, CeTSAF, Göttingen

[4] Tchale, H., Kachule, R., Mataya, C. (2003). Management of Miombo Woodlands in Malawi: An Application of Goal Programming, In: Policies and Governance Structures in Woodlands of Southern Africa, Kowero, G., Campbell, B. M., Sumaila, U. R. (Ed.), pp. 307-333, Center for International Forestry Research, ISBN 979-3361-22-0, Jakarta, Indonesia.

[5] Anderson, A. M. and Earle, M. D. (1983). Diet Planning in the Third World by Linear and Goal Programming, The Journal of the Operational Research Society, Vol. 34, No. 1, January 1983, pp. 9-16, ISSN: 0160-5682

[6] McCann-Rugg, M., White, G. P., Endres, J.M. (1983). Using Goal Programming To Improve The Calculation Of Diabetic Diets, Computers \& Operations Research, Vol. 10, No. 4, 1983, pp 365373, ISSN 0305-0548

[7] Leslie, P. W., Bindon, J. R., Baker, P. T. (1984). Caloric Requirements of Human Populations: A Model, Human Ecology, Vol. 12, No. 2, June 1984, pp. 137-162, ISSN 0300-7839

[8] Pasic, M., Catovic, A., Bijelonja, I. \& Crnovrsanin, S.: Linear Programming Local Cost Nutrition Optimization Model, Annals of DAAAM for 2011 \& Proceedings of the 22nd International DAAAM Symposium, ISBN 978-3-901509-83-4, ISSN 1726-9679, pp. 0389-0390, Editor B[ranko] Katalinic, Published by DAAAM International, Vienna, Austria, 2011 